\title{
Pengembangan Laboratorium Virtual Fisika Osilasi
}

\author{
Adhi Rizal ${ }^{1}$, Riza Ibnu Adam ${ }^{2}$, Susilawati ${ }^{3}$ \\ ${ }_{1,2,3}$ Universitas Singaperbangsa Karawang \\ 11 adhi.rizal@ staff.unsika.ac.id, ${ }^{2}$ riza.adam@staff.unsika.ac.id, ${ }^{3}$ susilawati.sobur@staff.unsika.ac.id
}

\begin{abstract}
This research aims to develop a virtual lab application with oscillation concept. Oscillation concept in this application is described as pendulum motion. The application was developed by using the ADDIE model and Easy Java Simulations (EJSs) software. It has advantages compared with similar applications, which has a damping coefficient that similar with real world condition. Some other features of the application are the users can run and pause the simulation, observe the details of changes in pendulum movement angle by using step forward button, users can change pendulum mass, adjust the length of the rope, gravitational force, initial angle, damping coefficient, and can observe the change of pendulum angular position in parabolic graphs in real-time. The application was tested using the Technology Acceptance Model (TAM) concept. Based on the research results, the user satisfaction level is categorized as very useful. Therefore, it can be conclude that the application can be accepted and used well by the user.
\end{abstract}

Keywords- EJSs, oscillation, Technology Acceptance Model, virtual lab

\begin{abstract}
Abstrak-Penelitian ini bertujuan untuk mengembangkan aplikasi laboratorium virtual dengan konsep osilasi berupa gerak pendulum. Pengembangan aplikasi dilakukan dengan menggunakan model ADDIE dan perangkat lunak Easy Java Simulations (EJSs). Aplikasi yang dikembangkan memiliki kelebihan dibandingkan dengan aplikasi sejenis, yaitu memiliki koefisien redaman sesuai dengan kondisi di dunia nyata. Beberapa fitur lain pada aplikasi ini yaitu yaitu pengguna dapat menjalankan dan menghentikan sementara (pause) simulasi, mengamati rincian perubahan sudut pergerakan pendulum dengan menggunakan tombol step forward, mengatur panjang tali, massa pendulum, besar gaya gravitasi, besar sudut, besar redaman, dan dapat melihat perubahan posisi sudut yang ditunjukan dalam bentuk grafik parabola secara real-time. Selain itu, aplikasi diuji dengan menggunakan konsep Technology Acceptance Model. Berdasarkan hasil penelitian, tingkat kepuasan pengguna berada pada kategori very useful. Hal ini menunjukan bahwa aplikasi yang dikembangkan dapat diterima dan digunakan dengan baik oleh pengguna.
\end{abstract}

Kata kunci- EJSs, fisika osilasi, laboratorium virtual, Technology Acceptance Model

\section{PENDAHULUAN}

Seiring dengan berkembangnya teknologi informasi, banyak produk-produk digital yang telah dikembangkan. Salah satu pemanfaatan teknologi ini terdapat dalam proses pembelajaran. Hal ini selaras dengan pendapat [1] yang menyatakan bahwa lingkungan belajar-mengajar telah berubah secara signifikan selama 50 tahun terakhir, yang sebagian besar disebabkan oleh pengaruh teknologi informasi dan komunikasi. Beberapa contoh dari lingkungan belajar misalnya ruang kelas, tempat kerja, laboratorium, museum, situs alam, sarana transportasi, rumah, dan sebagainya. Sebagian besar lingkungan belajar dirancang dan diimplementasikan agar dapat merangsang minat peserta didik dalam proses pembelajaran sehingga tujuan pembelajaran dapat terpenuhi dengan efektif. Oleh karena itu, lingkungan belajar harus disesuaikan dengan tujuan dan indikator pembelajaran misalnya dengan cara menerapkan pembelajaran yang berpusat pada peserta didik (studentcentered learning), insentif (proses psikologikal untuk merangsang motivasi), mengembangkan bahan ajar, tugas, tes, dan umpan balik [2].
Di dalam dunia pendidikan, khususnya pada mata pelajaran eksak, seringkali ditemukan bahwa peserta didik memiliki pemahaman yang berbeda satu sama lain dalam hal konsep yang diterima oleh para ahli ataupun secara ilmiah. Perbedaan pemahaman konsep ini biasa disebut dengan miskonsepsi [3]. Oleh karena itu dibutuhkan suatu cara yang efektif dan efisien agar peserta didik memiliki pemahaman tentang konsep, prinsip, hukum, dan teori yang tentang suatu materi pelajaran. Untuk mencapai tujuan tersebut, banyak cara dapat dilakukan, diantaranya dengan mengidentifiakasi dan menentukan metode, teknik, media, atau evaluasi yang sesuai, dan sebagainya. Berdasarkan hal tersebut, salah satu salah satu metode yang dapat mengatasinya adalah metode praktikum [4]. Dengan adanya praktikum diharapkan peserta didik dapat lebih memahami materi ajar karena mereka dapat melakukan eksplorasi, membuktikan, atau menguji kebenaran secara nyata tentang suatu konsep yang dipelajari.

Dibalik banyaknya manfaat yang ditawarkan dari metode praktikum, pada pelaksanaannya dibutuhkan alatalat praktikum yang digunakan untuk melakukan eksperimen. Hal ini bertolak belakang dengan kondisi 
beberapa sekolah di Indonesia yang masih memiliki kekurangan sarana dan prasarana, misalnya kuranganya ruangan kelas dan perangkat laboratorium. Hal demikian juga dialami oleh beberapa sekolah menengah yang ada di Kabupaten Karawang. Hal ini disebabkan karena ada beberapa sekolah yang baru menerima UGB (Unit Gedung Baru). Namun pada pelaksanaannya proses penyaluran dana dan pembangunannya tidak selalu tepat waktu. Hal ini menyebabkan hanya beberapa kelas atau ruangan belajar yang dapat digunakan untuk proses pembelajaran.

Terbatasnya bangunan untuk melaksanakan pembelajaran berdampak juga pada terlaksananya proses praktikum. Hal ini juga menyebabkan terbatasnya sarana laboratorium pada sekolah. Hal ini tentu saja menjadi faktor penghambat untuk melaksanakan kegiatan praktikum. Padahal praktikum merupakan suatu kegiatan pembelajaran yang harus dilaksanakan untuk membentuk pembelajaran yang bermakna pada peserta didik. Oleh karena itu, untuk mengatasi masalah tersebut, salah satu solusi agar makna dari pembelajaran tetap dapat dirasakan oleh peserta didik atau sebagai alternatif praktikum real adalah dengan cara melaksanakan kegiatan praktikum secara virtual. Praktikum virtual merupakan suatu kegiatan dalam lingkup laboratorium yang disajikan dalam bentuk digital di dalam komputer. Praktikum virtual ini juga membutuhkan suatu laboratorium yang juga bersifat virtual, atau dalam hal ini biasa disebut dengan laboratorium virtual. Laboratorium virtual yang merupakan simulasi komputer ini digunakan karena konsep pembelajaran Fisika paling baik dipelajari melalui investigasi melalui eksplorasi secara langsung penggunanya [5]. Manfaat laboratorium virtual muncul ketika penggunanya dapat menginvestigasi fenomena yang tidak teramati dan tidak ditemukan ketika melakukan investigasi menggunakan perangkat fisik, melakukan experimen yang lebih banyak dibandingkan dengan konfigurasi secara fisik, menghubungkan fenomena atau kejadian yang teramati pada tingkat atomik, atau untuk lebih memmperjelas perbedaan atau persamaan suatu fenomena atau kejadian [6].

Berdasarkan latar belakang dan permasalahan tersebut, maka penelitian ini bertujuan untuk mengembangkan laboratorium virtual pada mata pelajaran fisika dengan pokok bahasan mengenai osilasi. Simulasi fisika osilasi dikembangkan dengan menggunakan perangkat lunak Easy Java Simulations yang dibangun berdasarkan bahasa pemrogaman Java dan merupakan aplikasi open source.

\section{METODE PENELITIAN}

Penelitian ini bertujuan untuk mengembangkan dan mengimplementasikan produk yang dihasilkan. Produk yang dihasilkan adalah laboratorium virtual berupa aplikasi media untuk konsep osilasi. Subyek penelitian adalah salah satu kelas pada jenjang SMA (Sekolah Menengah Atas).
Secara umum, model pengembangan aplikasi yang digunakan pada penelitian ini adalah model ADDIE (Analysis, Design, Development, Implementation, dan Evaluation) [7].

\section{A. TEKNIK ANALISIS DATA}

Data-data yang dianalisis pada penelitian diperoleh dari hasil kuesioner yang dikembangkan berdasarkan pendekatan TAM kepada pengguna. Kuesioner dikembangkan berdasarkan Skala Likert yang bertujuan untuk mengukur sikap, pendapat, dan persepsi seseorang atau kolompok orang tentang suatu fenomena. Kelebihan dari skala Likert dibandingkan dengan skala pengukuran yang lain adalah mudah dipahami dan sederhana [8]. Skala Likert yang digunakan terdiri dari 5 kategori, yatu sangat setuju, setuju, ragu-ragu/netral, tidak setuju, dan sangat tidak setuju.

Berdasarkan hasil kuesioner dari pengguna, maka tahap selanjutnya dilakukan perhitungan untuk kemudian diklasifikasi ke dalam beberapa tingkatan penerimaan. Tingkatan penerimaan pengguna terhadap sistem yang dikembangkan dilakukan dengan menggunakan metode rating scale. Hasil yang diperoleh dari responden dapat diklasifikasikan ke dalam 4 kategori sepeti yang ditunjukan pada Gambar 1.

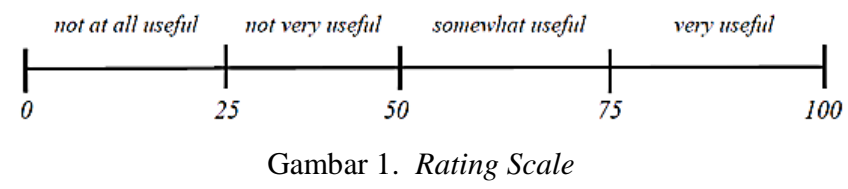

\section{A. Tahap Analisis \\ III. HASIL DAN PEMBAHASAN \\ Pada tahap ini dilakukan pendefinisian masalah,} analisis pengguna, dan kajian atau sudi literatur mengenai konten dan pembelajaran. Masalah yang terdapat pada subyek penelitian adalah belum adanya laboratorium untuk menyelenggakaran kegiatan praktikum fisika. Hal ini menyebabkan kegiatan belajar-mengajar tidak dapat diselenggarakan dengan efektif. Guru harus menjelaskan suatu konsep tanpa didukung dengan alat bantu mengajar (peralatan praktikum). Sehingga penyampaian materi oleh guru dan perolehan pemahaman bagi peserta didik berjalan dengan lambat bahkan terjadi miskonsepsi pada peserta didik [9].

Pengguna laboratorium virtual yang dikembangkan pada penelitian ini adalah Guru dan peserta didik kelas XI SMA. Konten atau materi pembelajaran yang diterapkan dalam aplikasi laboratorium virtual ini adalah pelajaran Fisika dengan sub pokok bahasan Osilasi.

Selain itu, analisis juga dilakukan untuk mengembangkan laboratorium virtual yang akan dikembangkan. Laboratorium virtual dengan konsep osilasi (gerak bandul) harus memiliki perbedaan atau keunikan dibandingkan dengan aplikasi sejenis dari penelitian lain. Berdasarkan hal tersebut, maka aplikasi yang dikembangkan memiliki kelebihan dari sisi fitur. Fitur tersebut adalah redaman. Redaman yang dimaksud 
adalah hambatan dari gaya gravitas dan gaya gesek dengan udara, sehingga bandul berhenti ke posisi setimbang.

\section{B. Tahap Perancangan}

Setelah tahap analisis dilakukan, selanjutnya adalah tahap perancangan Pada tahap ini dilakukan perancangan aplikasi dan perancangan skenario pengujian aplikasi.

Laboratorium virtual konsep osilasi ini berbentuk bandul yang diikatkan dengan tali sehingga dapat bergerak bolak-balik. Osilasi atau getaran adalah gerak bolak-balik di sekitar posisi setimbang [10]. Selain itu aplikasi yang dikembangkan memiliki beberapa fitur, yaitu pengguna dapat menjalankan dan menghentikan sementara (pause) simulasi, mengamati rincian perubahan sudut pergerakan bandul dengan menggunakan tombol step forward, mengatur panjang tali, massa bandul, besar gaya gravitasi, besar sudut, besar redaman, dan dapat melihat perubahan posisi sudut yang ditunjukan dalam bentuk grafik parabola secara real-time.

Agar simulasi yang dimodelkan serupa dengan gerak bandul sebenarnya, maka dalam penelitian ini, gerak osilasi pada bandul dimodelkan sesuai dengan model fisis. Secara spesifik bandul atau pendulum sederhana yang terdapat pada aplikasi laboratorium virtual ini dimodelkan oleh persamaan diferensial, yaitu persamaan (1).

$$
\frac{d^{2} \theta}{d t^{2}}=-\frac{g \sin \theta}{L}
$$

Dimana $\theta$ adalah posisi sudut pendulum $\left({ }^{\mathrm{O}}\right), g$ adalah percepatan gravitasi $\left(\mathrm{m} / \mathrm{s}^{2}\right), L$ adalah panjang tali $(\mathrm{m})$, dan $t$ adalah waktu (s). Disini kami menambahkan parameter redaman $b$ sehingga diperoleh persamaan (2), persamaan pendulum teredam.

$$
\frac{d^{2} \theta}{d t^{2}}=-\frac{g \sin \theta}{L}-\frac{b}{m L^{2}} \frac{d \theta}{d t}
$$

Dengan $m$ adalah massa pendulum $(K g)$ dan $b$ adalah konstanta redaman $(\mathrm{Ns} / \mathrm{m})$.

Secara umum persamaan (2) merupakan persamaan differensial orde 2. Solusi persamaan differensial orde 2 dapat diselesaikan secara numerik menggunakan metode runge kutta orde 4. Dimana untuk menyelesaikan persamaan ini harus diubah ke orde 1 dengan memisalkan persamaan (3) dan persamaan (4), sehingga diperoleh persamaan (5).

$$
\begin{gathered}
\frac{d \theta}{d t}=\omega \\
\frac{d^{2} \theta}{d t^{2}}=\frac{d \omega}{d t} \\
\frac{d \omega}{d t}=-\frac{g \sin \theta}{L}-\frac{b}{m L^{2}} \omega
\end{gathered}
$$

Pada tahap pengujian, penelitian ini menggunakan pengujian untuk mengetahui penerimaan pengguna berdasarkan model TAM (Technology Acceptance Model). TAM merupakan salah satu model yang dikembangkan untuk menganalisis dan memahami faktorfaktor yang mempengaruhi penerimaan penggunaan teknologi komputer. TAM bertujuan untuk menjelaskan dan memprediksi tingkat penerimaan (acceptance) pengguna terhadap suatu teknologi berbentuk perangkat keras, perangkat lunak, maupun keduanya. Berdasarkan Gambar 1, maka pada penelitian ini akan dikembangkan kuesioner dengan variabel-variabel berupa komponen yang terdapat pada TAM, yaitu Perceived Ease of Use (PEOU), Perceived Usefulness (PU), Attitude Toward Using (ATU), Behavioral Intention to Use (BITU), dan Actual Use (AU) [11].

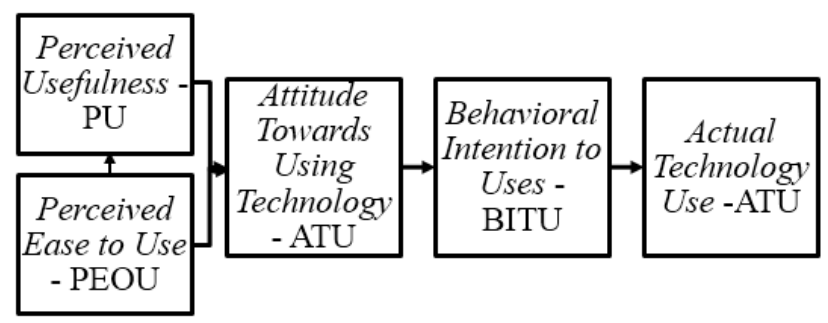

Gambar 2. Technology Acceptance Model (TAM) [11]

\section{Tahap Pengembangan}

Berdasarkan tahap analisis dan perancangan, maka tahap berikutnya yang dilakukan adalah pengembangan aplikasi laboratorium virtual.

Gambar 3 menunjukan variabel-variabel yang digunakan ke dalam model simulasi gerak pendulum berdasarkan Persamaan (5). Sedangkan Gambar 4 menunjukan variabel yang digunakan untuk menampilkan grafik posisi angular pendulum secara real-time.

Secara lebih rinci, berdasarkan persamaan Gambar (3), Gambar (5), dan Persamaan (5) model pendulum ini memiliki variabel pokok yaitu $\theta, g, L, t, b, m$, dan $\omega$. Variabel tersebut merupakan variabel dinamis yang dapat diubah-ubah. Sedangkan variabel pelengkap seperti $x_{0}, y_{0}$, $x$ dan $y$ merupakan variabel pelengkap untuk menyimpan titik vektor pada koordinat kartesian, sisanya kami menambahkan variabel lain ( $d t$ dan angle) hanya untuk mempermudah proses konversi perhitungan.

Gambar 6 menunjukan elemen atau komponenkomponen yang digunakan untuk membuat antarmuka aplikasi. Tampilan aplikasi terdiri dari 3 komponen utama, yaitu jendela utama (main window), jendela grafik pergerakan pendulum, dan jendela bantuan. Jendela utama berfungsi untuk menempatkan tombol-tombol yang berfungsi untuk melakukan konfigurasi terhadap gerakan pendulum serta untuk menempatkan gambar model pendulum yang akan bergerak ketika simulasi dijalankan. Jendela grafik pergerakan pendulum adalah jendela untuk menampilkan posisi angular/sudut pendulum terhadap waktu ketika simulasi dijalankan. Sedangkan jendela bantuan berfungsi untuk menampilkan menu bantuan untuk mempermudah pengguna dalam menggunakan aplikasi ini. 


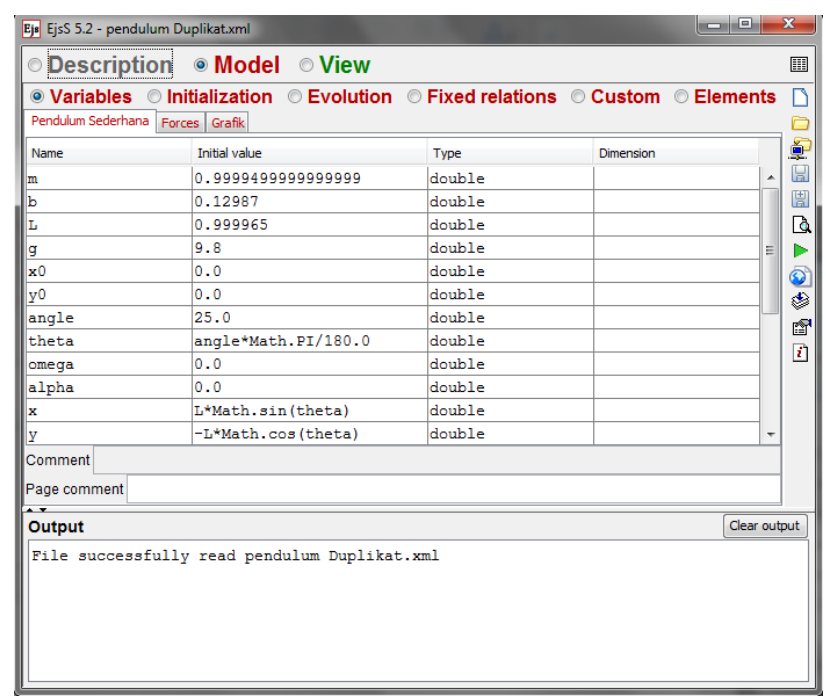

Gambar 3. Inisialisasi Variabel Pada EJS

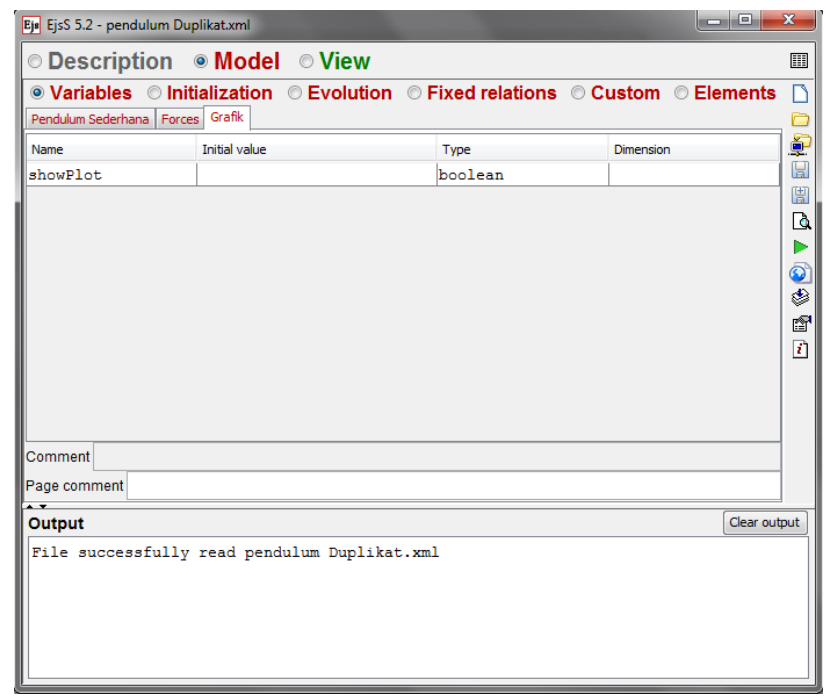

Gambar 4. Variabel Untuk Menampilkan Grafik Posisi Angular Pendulum

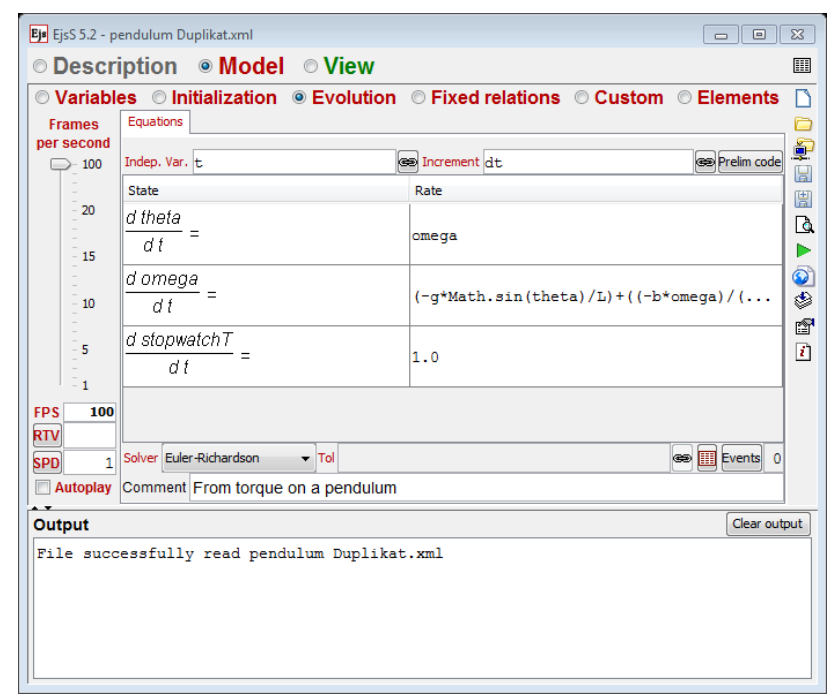

Gambar 5. Persamaan Gerak Pendulum

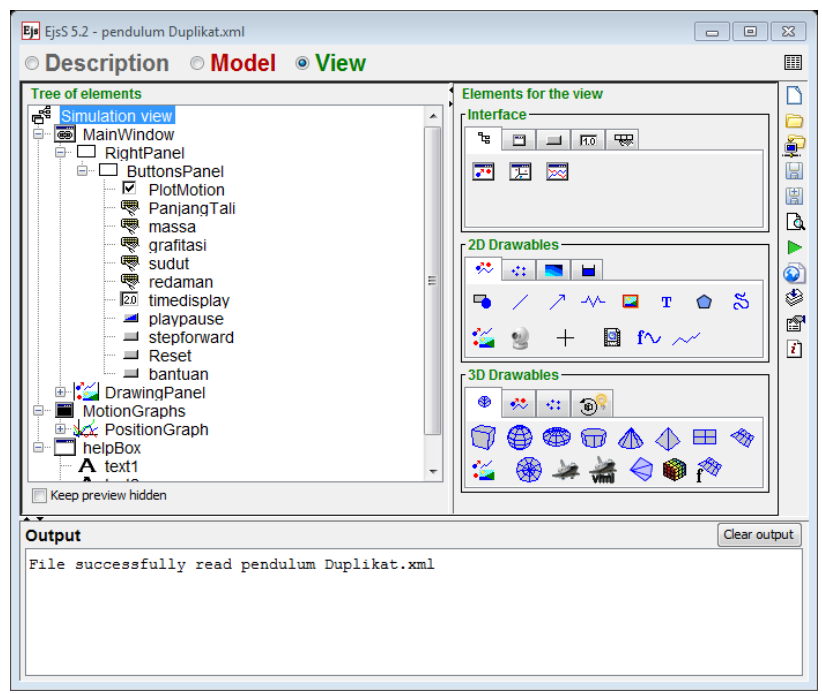

Gambar 6. Komponen View Untuk Antarmuka Aplikasi

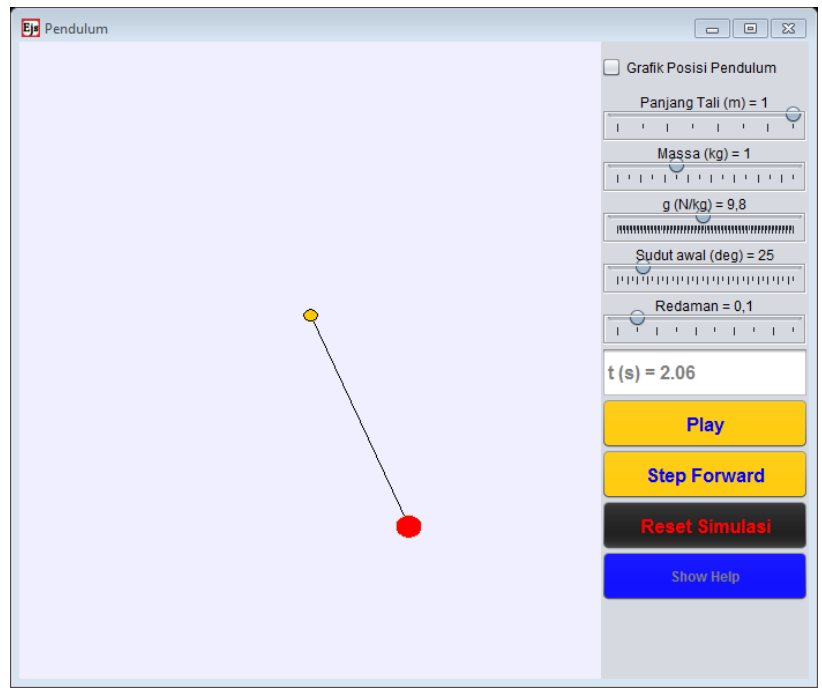

Gambar 7. Tampilan Utama Aplikasi Laboratorium Virtual Pendulum

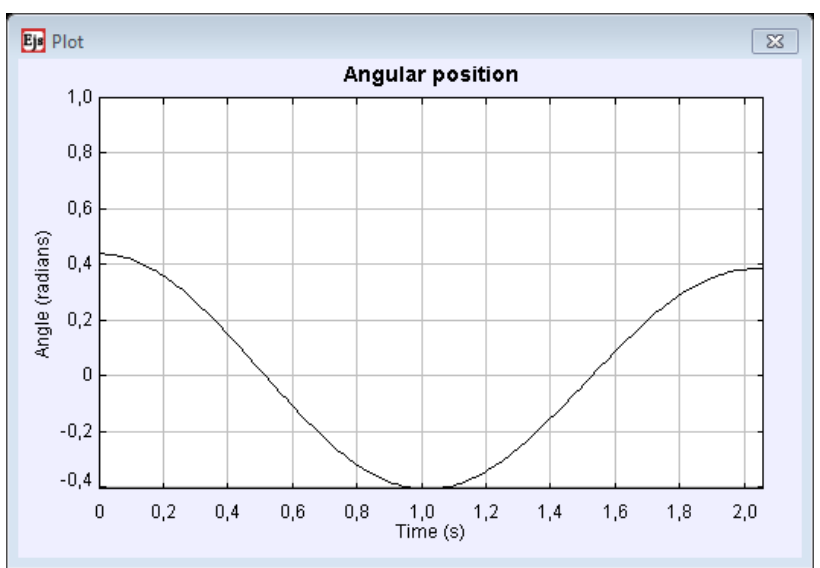

Gambar 8. Grafik Perubahan Sudut Pendulum Terhadap Waktu 


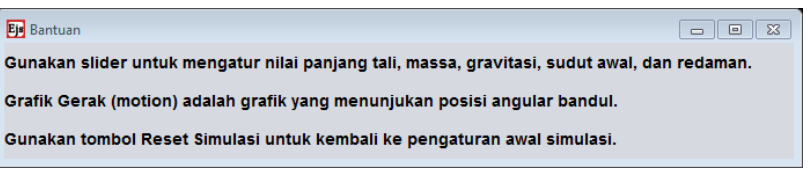

Gambar 9. Menu Bantuan Aplikasi Laboraturim Virtual Pendulum

Gambar 7, Gambar 8, dan Gambar 9 merupakan tampilan keseluruhan aplikasi. Gambar 7Error! Reference source not found. adalah tampilan jendela utama aplikasi ketika dijalankan. Jendela utama ini terdiri dari model pendulum, checkbox Grafik Posisi Pendulum untuk menampilkan grafik parabola yang menunjukan sudut pendulum per satuan waktu secara real-time (Gambar 8), 5 buah slider untuk konfigurasi percobaan pendulum, waktu yang berjalan ketika simulasi dijalankan, dan 4 buah tombol.

Gambar 8 merupakan grafik angular position yang menunjukan perubahan posisi sudut bandul terhadap waktu. Gambar 8 berfungsi untuk melihat perubahan amplitudo setiap detik. Pada Gambar 8 dapat terlihat bahwa penurunan amplitudo setiap detiknya ketika redaman bernilai lebih dari 0 .

Panjang tali dengan satuan meter memiliki nilai paling rendah (Panjang tali minimum) 0,3 sedangkan nilai maksimum (panjang tali maksimum) adalah 1. Slider panjang tali memiliki interval sebesar 0,1 untuk setiap Perubahan panjangnya. Semakin panjang tali, maka pendulum akan bergeser menjauhi titik tumpu.

Massa pendulum dengan satuan kilogram memiliki nilai paling rendah (massa minimum) 0,5 sedangkan nilai maksimum (massa maksimum) adalah 2. Slider massa pendulum memiliki interval sebesar 0,1 untuk setiap perubahan massanya. Semakin besar massa pendulum, maka gambar pendulum pada aplikasi juga akan semakin membesar.

Gaya gravitasi dengan satuan $\mathrm{N} / \mathrm{Kg}$ memiliki nilai paling rendah (gravitasi minimum) 0 sedangkan nilai maksimum (gravitasi maksimum) adalah 20. Slider gravitasi ini memiliki interval sebesar 0,1 untuk setiap perubahan gravitasinya.

Besar sudut pendulum dengan satuan $\left(^{\circ}\right)$ memiliki nilai paling rendah (sudut terkecil) 0 sedangkan nilai maksimum (sudut terbesar) adalah $175^{\circ}$. Slider sudut pendulum memiliki interval sebesar 0,1 untuk setiap perubahan sudutnya. Sudut $0^{\circ}$ menunjukan bahwa pendulum berada pada titik kesetimbangannya, yaitu tegak lurus dengan sumbu X. Sedangkan semakin besar sudut yang ditentukan, maka pendulum akan bergeser semakin jauh dari posisi kesetimbangannya berlawanan arah dengan jarum jam.

Redaman memiliki nilai paling rendah (redaman minimum) 0 sedangkan nilai maksimum (redaman maksimum) adalah 1. Slider redaman ini memiliki interval sebesar 0,1 untuk setiap perubahan redamannya. Semakin kecil redaman, maka osilasi yang terjadi akan semakin banyak, sehingga pendulum lebih lama mencapai titik kesetimbangannya kembali. Sebaliknya, semakin besar redaman, maka osilasi yang terjadi akan semakin sedikit, sehingga pendulum lebih cepat mencapai titik kesetimbangannya kembali.

Tombol Play berfungsi untuk menjalan simulasi. Ketika simulasi dijalankan, maka tombol Play akan berubah menjadi tombol Pause. Tombol Pause berfungsi untuk menghentikan simulasi sementara. Tombol Step Forward berfungsi untuk menjalankan simulasi tetapi setiap 0,01 detik. Hal ini berfungsi agar pengguna dapat mengamati pergerakan pendulum secara lebih rinci. Tombol Tampilkan Bantuan berfunsi untuk menampilkan jendela bantuan yang berisi informasi mengenai petujuk penggunaan aplikasi. Jendela bantuan ini ditunjukan pada Gambar 9.

\section{Tahap Implementasi}

Aplikasi laboratorium virtual yang telah dikembangkan kemudian akan diterapkan pada salah satu kelas pada kelas XII. Jumlah peserta didik yang berpatisipasi dalam pengisian kuesioner adalah berjumlah 23 oang. Proses implementasi ini bertujuan untuk mengetahui sejauh mana aplikasi yang dikembangkan dapat diterima dan digunakan oleh pengguna.

\section{E. Tahap Evaluasi}

Tahap evaluasi dilakukan terhadap implementasi aplikasi laboratorium virtual yang telah dikembangkan. Pada penelitian ini evaluasi akan dilakukan dengan kuesioner menggunakan model pendekatan TAM untuk mengetahui penerimaan pengguna terhadap aplikasi yang diujicobakan. Tabel 2 di bawah ini menunjukan hasil tingkat penerimaan pengguna terhadap aplikasi yang telah dikembangkan.

Tabel 1. Hasil Uji Penerimaan Pengguna dengan Instrumen

\begin{tabular}{ll}
\multicolumn{1}{c}{ Kuesioner } \\
\hline \multicolumn{1}{c}{ Variabel } & Nilai \\
\hline Perceived Usefulness (PU) & 79,13 \\
\hline Perceived Ease-of-Use (PEOU) & 80,87 \\
\hline Attitude Toward Using (ATU) & 78,26 \\
\hline Behavioral Intention to Use (BITU) & 78,84 \\
\hline Actual Use (AU) & 80 \\
\hline Rata-rata & 79,42 \\
\hline
\end{tabular}

Berdasarkan di atas terlihat bahwa nilai dari seluruh nilai yang diperoleh pada setiap variabel TAM berada pada kategori very useful atau sangat berguna atau sangat memuaskan. Selain itu, jika dilihat secara keseluruhan (berdasarkan rata-rata nilai seluruh variabel) diperoleh nilai sebesar 79,42. Nilai tersebut berada pada kategori very userful. Berdasarkan hal tersebut dapat disimpulkan bahwa aplikasi yang dibuat dapat memberikan nilai kepuasan yang tinggi kepada setiap penggunanya.

\section{IV.PENUTUP}

Berdasarkan hasil penelitian, aplikasi laboratorium virtual dengan konsep osilasi berupa gerak pendulum telah berhasil dikembangkan. Pengembangan aplikasi dilakukan dengan menggunakan model ADDIE. Aplikasi yang dikembangkan memiliki kelebihan dibandingkan dengan aplikasi sejenis, yaitu memiliki koefisien redaman 
sesuai dengan kondisi di dunia nyata. Beberapa fitur lain pada aplikasi ini yaitu yaitu pengguna dapat menjalankan dan menghentikan sementara (pause) simulasi, mengamati rincian perubahan sudut pergerakan pendulum dengan menggunakan tombol step forward, mengatur panjang tali, massa pendulum, besar gaya gravitasi, besar sudut, besar redaman, dan dapat melihat perubahan posisi sudut yang ditunjukan dalam bentuk grafik parabola secara real-time. Selain itu, pengembangan aplikasi laboratorium virtual fisika osilasi berhasil diterapkan. Hal ini terlihat dari tingkat kepuasan pengguna yang berada pada kategori very useful dengan nilai rata-rata sebesar 79,42 .

\section{REFERENSI}

[1] J. M. Spector, "Conceptualizing the emerging field of smart learning environments," Smart Learning Environments, 2014.

[2] H. Jin, " The Design of Combined Platform for Web-Based Cooperative Learning," in Scalable Computing and Communications; Eighth International Conference on Embedded Computing, 2009. SCALCOMEMBEDDEDCOM'09, Dalian, 2009.

[3] G. Zhou, N. Nocente and W. Brouwer, "Understanding Student Cognition Through an Analysis of Their Preconceptions in Physics," The Alberta Journal of Educational Research, pp. 14-29, 2008.

[4] H.-D. Barke, A. Hazari and S. Yitbarek, Misconceptions in Chemistry, Heidelberg: Springer-Verlag Berlin Heidelberg, 2009.

[5] L. Kang Wee, G. Hwee Goh and E.-P. Lim, "Easy Java Simulation, Innovative Tool For Teachers As Designers Of Gravity-Physics Computer Models," in MPTL18th Multimedia in Physics Teaching and Learning Conference, Madid, 2013.

[6] T. d. Jong, M. C.Linn and Z. C.Zacharia, "Physical and Virtual Laboratories in Science and Engineering Education," Grand Cahallenges in Science Education2013, 19 April 2013.

[7] C. Peterson, "Bringing ADDIE to Life: Instructional Design at Its Best," Journal of Educational Multimedia and Hypermedia, pp. 227-241, 2003.

[8] Suliyanto, "Pebedaan Pandangan Skala Likert sebagai Skala Ordinal atau Skala Interval," in Prosiding Seminar Nasional Statistika, Semarang, 2011.

[9] J. Handhika, E. Kurniadi and I. Muda, "Pengembangan Media Pembelajaran Bermuatan Konflik Kognitif Untuk Mengurangi Dugaan Miskonsepsi Pada Matakuliah Fisika Dasar," Jurnal Materi dan Pembelajaran Fisika (JMPF), pp. 8-13, 2014.

[10] M. Abdullah, Fisika Dasar I, Bandung: Institut Teknologi Bandung, 2016.

[11] A. Wahyudin, Munir and S. Soviani, "Tingkat Penerimaan Media Video Conference dalam Proses Pembelajaran dengan menggunakan Technology Accepted Model
(TAM)," Jurnal Pendidikan Teknologi Informasi Dan Komunikasi, 2011. 